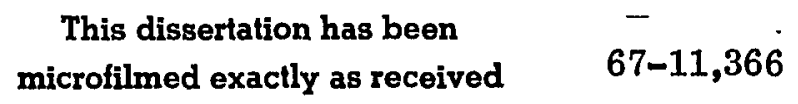

University Microfilms, Inc., Ann Arbor, Michigan 


\section{AWARENESS AND THE OPERANT CONDITIONING \\ OF A COOPERATIVE RESPONSE}

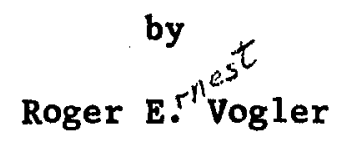

A Dissertation Submitted to the Faculty of the DEPARTMENT OF PSYCHOLOGY

In Partial Fulfillment of the Requirements For the Degree of

DOCTOR OF PHILOSOPHY

In the Graduate College

THE UNIVERSITY OF ARIZONA

1967 
THE UNIVERSITY OF ARIZONA

GRADUATE COLLEGE

I hereby recommend that this dissertation prepared under my direction by Roger Ernest Vogler

entitled Awareness and the Operant Conditioning of a

Cooperative Response

be accepted as fulfilling the dissertation requirement of the degree of Doctor of Philosophy

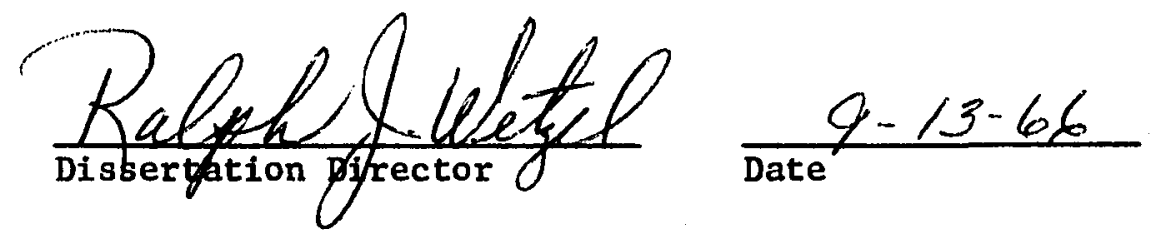

After inspection of the dissertation, the following members of the Final Examination Committee concur in its approval and recommend its acceptance:*
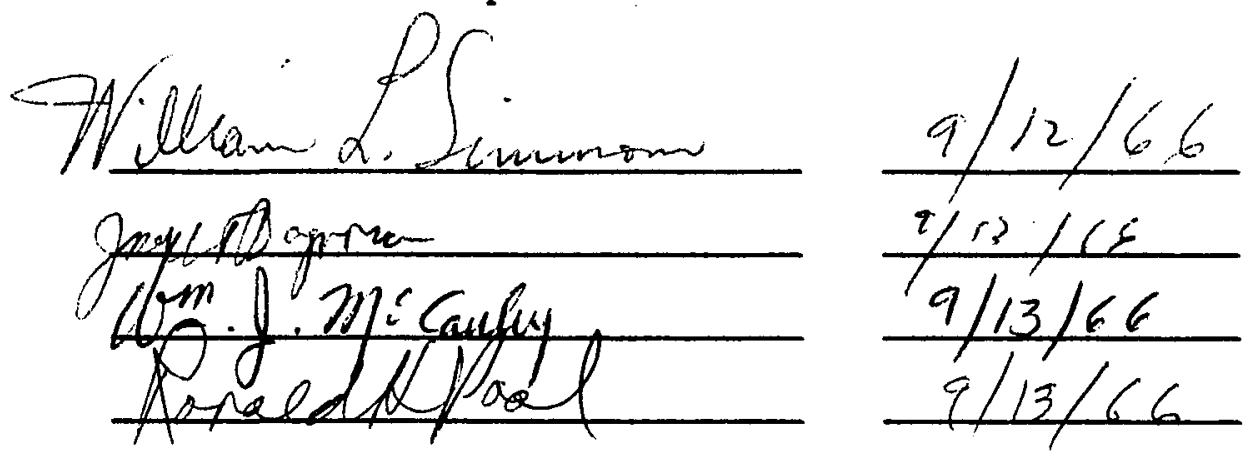

*This approval and acceptance is contingent on the candidate's adequate performance and defense of this dissertation at the final oral examination. The inclusion of this sheet bound into the library copy of the dissertation is evidence of satisfactory performance at the final examination. 
This dissertation has been submitted in parital fulfillment of requirements for an advanced degree at the University of Arizona and is deposited in the University Library to be made available to borrowers under the rules of the Library.

Brief quotations from this dissertation are allowable without special permission, provided that accurate acknowledgment of source is made. Requests for permission for extended quotation from or reproduction of this manuscript in whole or in part may be granted by the head of the major department or the Dean of the Graduate College when in his judgment the proposed use of the material is in the interests of scholarship. In a 11 other instances, however, permission must be obtained from the author.

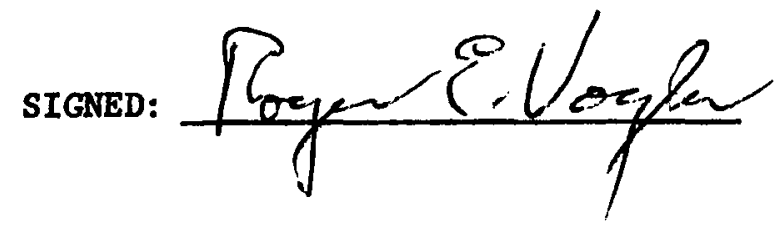




\section{ACKNOWLEDGENTS}

The author is indebted to his director, Dr. Ralph J. Wetzel, for his assistance in the design of the study and his critical evaluation of the manuscript. The author is grateful to Drs. William L. Simmons and Ronald H. Pool for their valuable advice in carrying out the experiment and their critical comments on the manuscript. A special debt of gratitude is owed John Dohme for the willingness with which he applied his knowledge of electronics and his technical skill to the construction of the apparatus. The author is most thankful to his wife, Mrs. Lynda L. Vogler, Dr. Daniel L. Logan, and Fredric L. Johnson, for their help in running the experiments. A particular note of apprectation must be made for the exceptional cooperation of $\mathrm{Dr}$. Kenneth Johns, Director of the Summer Enrichment Program in the College of Education, Mrs. Mary Ellwood, teacher of the class from which the children were drawn, and the many parents who permitted their children to participate in the study. 
TABLE OF CONTENTS

Page

LIST OF ILLUSTRATIONS . . . . . . . . . . . . . . . . v v

LIST OF TABLES. . . . . . . . . . . . . . . . . . . vi

ABSTRACT. . . . . . . . . . . . . . . . . . . v vii

INTRODUCTION. . . . . . . . . . . . . . . . . 1

METHOD. . . . . . . . . . . . . . . . . . 10

Definition of the Cooperative Response. . . . . . . . 10

Definition of Awareness . . . . . . . . . . . . . 11

Subjects. . . . . . . . . . . . . . . . . . . . 12

Apparatus . . . . . . . . . . . . . . . 12

Procedure . . . . . . . . . . . . . . . 14

RESULTS . . . . . . . . . . . . . . . . . . . 17

Conditioning Performance of Aware vs. Unaware Subjects. . . 17

Tempora 1 Relationship of Awareness to Conditioning. . . . . 18

Variables Influencing Awareness . . . . . . . . . . . 21

DISCUSSION. . . . . . . . . . . . . . . . . . . 27

Conditioning Performance of Aware vs. Unaware Subjects. . . 27

Temporal Relationship of Awareness to Conditioning. . . . . 29

Variables Influencing Awareness . . . . . . . . . . . 31

SUMMARY . . . . . . . . . . . . . . . . . . 4 40

APPENDIX. . . . . . . . . . . . . . . . . . 4 43

LIST OF REFERENCES. . . . . . . . . . . . . . . . . . 44 


\section{LIST OF ILLUSTRATIONS}

Figure

Page

1. Experimental table at which the subjects were seated ...

2. Mean percent cooperative response rate curves for aware vs. unaware subjects. . . . . . . . . .

3. Mean percent cooperative responses per minute and per

five minute time blocks for aware subjects. . . . . 


\section{LIST OF TABIES}

Table

Page

1. A summary of mean percent cooperative response rate changes before and after verbalization of the contingency. . . . . . . . . . . . . .

2. A summary of total response rate data for aware and unaware subjects. . . . . . . . . . . . . 


\section{ABSTRACT}

Investigators with an operant conditioning orientation have produced evidence that conditioning can occur without awareness, whereas workers from a cognitive learning theory point of view, employing somewhat different experimetnal procedures, have obtained results supporting the hypothesis that conditioning only occurs in subjects who become aware of the response-reinforcement contingency. Moreover, cognitive theorists maintain that increments in conditioning performance occur only after awareness. The theory of Postman and Sassenrath, on the other hand, holds that some conditioning occurs prior to awareness and that awareness is both a result of past improvement and a condition of further improvement in conditioning performance. Important in generalizing about the role of awareness in conditioning is the fact that the present study was uniquely different from other studies of awareness in several ways. The reinforced response class was a physical one rather than a verbal one and involved the behavior of two individuals instead of one, candy instead of a verbal stimulus was used as the reinforcer, the experimental nature of the study was not apparent to the subjects, who were children rather than adu1ts, and most importantly, the experimental design was unique among studies of awareness in providing a sensitive measure of the temporal relationship of awareness to conditioning rate. The cooperative response was defined according to a four-dimenstonal scheme involving the sequential vs. non-sequential, latency, duration, and topography dimensions of the 
response. Three classes of verbal behavior were used to objectively define the requirements of awareness of the response-reinforcement contingency. The apparatus, the experimental procedure, and the method of recording behavioral observations ts described. Ten pairs of children six to eight years of age served as subjects. On the basis of verbalizations during the experiment, five pairs were classified as aware and five as unaware. Only the aware subjects conditioned thus supporting the hypothesis that awareness is necessary for conditioning to occur. An increase in conditioning rate was observed just prior to awareness, and an even greater increase occurred following awareness. These data support the Postman and Sassenrath position that awareness is both the result of past improvement and a condition of further improvement. Since al1 unaware subjects received some reinforcement and yet failed to become aware, the idea that the effects of reinforcement are "automatic," in the sense that reinforcement is a sufficient condition to bring about awareness, was not supported. The data suggest that reinforcement is a necessary condition for awareness to occur, and that other variables influencing awareness are partially correct hypotheses, total response rate, attention to the task, mutual compliance to test hypotheses, and the nature of the conditioning task. Each of these variables probably interacts with, or in some way is influenced by, reinforcement, instructions, and historical vartables. Manipulatable conditions which would enhance the liklihood of awareness, and hence conditioning, are: a response with a longer latency and a simpler topography; a restricted operant which would slow the total response rate and provide time between responses 
to observe the consequences of each response emitted; Instructions which induce a problem-solving set. As a cognitive process which may be an essential mediating event in the conditioning of many human behaviors, a detailed knowledge of the process itself and the conditions affecting it, especially those conditions which are more manipulatable, may have significant implications for behavior modification. 


\section{INTRODUCTION}

The role of awareness in the operant conditioning of human behavior has been given extensive attention. To date nearly all of the studies on awareness have involved the conditioning of verbal behavior (see reviews by Krasner, 1958; Salzinger, 1959; Greenspoon, 1962; Vogler, 1966a). Virtually all of these studies have been carried out either by investigators with an operant conditioning orientation, or by cognitive learning theorists.

The majority of the studies from a descriptive behavioristic, or operant conditioning, model provide evidence in support of the conclusion that verbal behavior is conditioned without the subjects' becoming aware of, i.e., being able to verbalize, the responsereinforcement contingency (e.g. approximately $95 \%$ of the subjects in the 31 studies reviewed by Krasner, 1958, were unaware). On the other hand, investigators from a cognitive learning theory point of view have produced evidence that conditioning performance gains are limited to only those subjects who become aware of the responsereinforcement contingency (e.g. DeNike and Spielberger, 1963; Dulany, 1962; Lanyon, 1964; Levin, 1961; Spielberger, Levin, and Shepard, 1962; Splelberger, Berger, and Howard, 1963). These contradictory conclusions are the result of theoretical and procedural differences between the two approaches.

Operant investigators want to demonstrate that verbal behavior is a function of reinforcement and can be modifled by traditional 
operant techniques; awareness may or may not be correlated with changes in verbal behavior, but regardless of whether it 18 or not, it is not conceptualized as a mediating variable affecting conditioning performance. Cognitive theorists conceptualize awareness both in terms of a dependent variable, the function of antecedent conditions, and as a mediating cognitive process affecting verbal conditioning performance; they have attempted to clarify the role of awareness, and to account for differences in their data as a function of awareness, both alone and in interaction with other variables. The two approaches also differ in their definition of what is learned in conditioning experiments. Increased emission of the reinforced response class is what is conditioned from a descriptive behaviorist's point of view. Awareness of the response-reinforcement contingency is what is learned from a cognitive theorist's viewpoint (who regards performance as a complex product of hypotheses and motives).

Two procedural differences represent most clearly the above theoretical differences. Since awareness is not essential to the main purpose of demonstrating relnforcement effects, the operant worker usually assesses awareness (operationally defines it) by asking subjects only a few, brief, open-ended questions at the end of the experiment. For example, in the Greenspoon study (1955) the response class "plural nouns" was brought under control of the reinforcing stimulus "Mmm-hm" In subjects classified as unaware on the basis of the following four questions: "(1) What do you think it was al1 about? (2) Did you notice any change in the kind of words you were saying? (3) What do you think the purpose of the 'Mmm-hmm' was? 
(4) How long do you think you were saying words?" The cognitively oriented investigator questions subjects more extensively about their awareness, usually proceeding from open-ended questions to more specific and detailed ones. For example, in a study by Spielberger (1962), beginning sentences with a class of pronouns selected from a choice of six pronouns written on a card, was brought under control of the reinforcing stimulus "Good," but only in subjects classified as aware on the basis of the following questions: "(1) Did you usually give the first sentence that came to your mind? (2) How did you go about deciding which of the words to use? (3) Did you think you were using some words more often than others? Which words? Why? (4) What do you think the purpose of this was? (5) While going through the cards did you think that you were supposed to make up your sentences in any particular way, or that you were supposed to change the way in which you made up your sentences? How? (6) Did you notice anything about the experimenter while you were going through the cards?" (For subjects who spontaneously verbalized awareness of the "Good" prior to Question 7, Questions 7 and 8 were omitted). "(7) Did you notice that she sald anything? (8) Actually she did occasionally say 'Good.' Thinking back now to when you were going through the cards, do you remember her saying 'Good'? (9) (Thinking back now to when you were going through the cards) What did her saying 'Good' mean to you? (10) Did you try to figure out what made her say 'Good' or why or when she was saying 'Good'? (11) What Ideas dịd you have about what vas making her say 'Good'? (12). While going through the cards, did you think that her saying 'Good' had anything to do with the words you chose to begin your sentences? What?" 
The above examples make it evident that awareness is operationa11y defined quite differently by operant and cognitive workers, and It is not surprising that cognitive workers generally classify a larger percentage of their subjects as aware.

The second essential procedural difference arises from the operant conditioners consideration of awareness solely as a dependent varlable. The number of subjects who become aware is usually reported, and the conditioning data for these subjects discarded before analyzing for reinforcing effects, since it is assumed that awareness may interfere with an appropriate demonstration of conditioning. The cognitive worker, on the other hand, regards awareness as a mediating cognitive variable affecting performance gains, and compares the conditioning data of aware and unaware subjects.

The main effect of these differences is that operant workers find few subjects who are aware, obtain reinforcement control over the selected response class of verbal behavior, and conclude that conditioning can occur without awareness. Cognitive investigators find more subjects who are aware, obtain conditioning for aware subjects only, and conclude that awareness is an essential mediating process in verbal conditioning. On the basis of two recent cognitive studies (DeNike, 1964; Spielberger, Bernstein and Ratliff, 1966) in which awareness was assessed during the experiment, as we11 as after it in the usual post-conditioning interview (PCI), the further assertion has been made that conditioning performance increments occur only after the response-reinforcement contingency is verbalized. 
In a discussion of the above two studies Spielberger and DeNike (1966) place heavy emphasis on the temporal relationship of awareness to conditioning in evaluating existing hypothetical explanations of the role of awareness. Both studies employed the same procedure, which was to have subjects write down their "thoughts about the experiment" after each trial block of words during the experiment. On1y aware subjects showed performance gains, and performance increments of aware subjects first occurred on the trial block after which they wrote their correct hypotheses in their notes. No performance gains for these subjects were recorded prior to the trial block after which they recorded their correct hypotheses, and unaware subjects did not differ from the randomly reinforced control group in their conditioning data. The authors concluded that awareness mediated performance gains, and that conditioning occurred only after awareness. With regard to the theory of Postman and Sassenrath (1961) that awareness is both a result of past improvement (manifested in performance increments prior to awareness and thus is conditioning without awarenëss) and a condition of further improvement (even greater performance increments after verbalization of the contingency), Spielberger and DeNike argue that such a theory would not explain the absence of performance gains for unaware subjects nor the absence of performance gains for aware subjects on preawareness word blocks. It would appear to the present author that the Postman and Sassenrath position is not necessarily untenable because of the failure of aware subjects to show performance gains until the word block after which they wrote down their correct hypotheses. Performance increments 
prior to awareness may be relatively $s m a 11$, and the experimental design in these studies is such that awareness is not assessed until after each block of 25 words. The data report only performance changes occurring sometime during a given trial block after which the subjects wrote down a correct hypothesis. Thus, it is still possible that increments in performance preceded awareness and went undetected. As for the argument that unaware subjects failed to show conditioning increments, it is reasonable to assume that other conditions in addition to reinforcement are also necessary to bring about awareness. Postman and Sassenrath contend that when awareness does occur, it is "a result of" learning prior to the subjects' verbalization of the response-reinforcement contingency. Aside from their contention that this preawareness conditioning is a function of the automatic effects of reinforcement, it may still be true that conditioning increments prior to awareness, whatever its cause or causes, is an essential prerequisite to becoming aware. It is also possible that this preawareness conditioning is both a necessary and sufficient condition for awareness, and that reinforcement and other variables bring about the preawareness conditioning, which leads to awareness, which then results in an even greater increase in conditioning rate. The essence of the disagreement between Postman and Sassenrath, and Spielberger and DeNike, seems to involve the role of reinforcement. In the Splelberger and DeNike studies, the fallure of unaware subjects and aware subjects to show conditioning increments on preawareness word blocks contraindicates the "automatic" effects of reinforcement, 1.e., the idea that reinforcement is a sufficient condition to effect 
acquisition of the response class upon which it is made contingent. On the other hand, the Postman and Sassenrath contention that conditioning increments prior to awareness (disregarding its causes) are necessary to bring about awareness, is a reasonable possibility, notwithstanding the Spielberger and DeNike evidence on the temporal relationship of awareness to conditioning rate, since their measure was not highly sensitive.

A compromise position would be that in order to bring about awareness, increments in conditioning rate prior to awareness may be necessary, reinforcement is a necessary but not sufficient condition, and other conditions as yet not clearly specified are also necessary. These other conditions may be such things as subjects' attention to the task, the response set of subjects, or their total rate of responding (time spent between words for thinking of hypotheses). Each of these variables is probably influenced to some extent by the interaction of reinforcement effects, instructions, and historical variables, and they might therefore be considered mediating variables themselves. Observations on them are not often reported in studies of awareness, much less a systematic investigation of how they might influence awareness, or the antecedent conditions affecting them. The present study was therefore planned not only to investigate the effects of awareness on conditioning rate, and to clarify their temporal relationship, but to obtain data on other events besides reinforcement which might be involved in becoming aware.

In a previous study on the operant conditioning of cooperation In children (Vogler, 1966b) there was evidence that awareness of the 
response-reinforcement contingency influenced the conditioning process In a systematic way. It appeared that pairs of subjects who verbalized the contingency showed the greatest conditioning of cooperative behavior. Pilot data for the present study indicated that it would be feasible to assess awareness from the conversation between subjects during the experiment. In fact, it was found that an experimental situation could be contrived which would make reinforcement highly contingent upon verbalizations about the contingency. This was done by making the cooperative response sufficiently difficult that subjects had to verbalize their thoughts about the contingency in order to coordinate their efforts to receive maximum reinforcement. In this way the temporal relationship between verbalizations of the contingency and conditioning performance could be studied.

Even though the present study used a physical response class rather than a verbal one, and involved the behavior of two persons rather than one, these unique differences for a study of awareness and conditioning were regarded as likely to produce results which might be useful in generalizing about the role of awareness in conditioning. Awareness could be assessed at any time during the experiment, since subjects were free to verbalize at any time and not just after given sets of trials. The cooperative nature of the response, and making reinforcement highly contingent upon the emission of verbalizations about the contingency during the experiment, increased the probability of a closer proximity between the occurrence of an hypothesis to a subject, and its verbalization. It was possible to 
record them on the same graph, and thus obtain a more sensitive measure of the temporal relationship of awareness to conditioning rate, than in other studies of awareness. At the same time observations could be made of the extent to which subjects attended to the task, or complied with each others suggestions, etc., variables which could Influence the conditioning process.

The study was thus planned to illuminate a number of questions about the role of awareness in the operant conditioning of human behavior. The behavior selected was chosen because of the liklihood of its providing unique data which would have implications for the conditioning process in general. Particular areas to be investigated were: Do aware subjects only condition? What is the temporal relationship of awareness to cooperative rate? What variables affect becoming aware? 
METHOD

Definition of the Cooperative Response

A four-dimensional scheme for defining a cooperative response according to explicit operational procedures was presented in an earlier paper (Vogler, 1966b). These dimensions are sequential vs. non-sequential, topography, latency, and duration. The sequential vs. non-sequential dimension refers to whether the individual responses alternated or were nearly synchronous. The topography of the cooperative response refers to the actual physical behavior which the individuals emit, such as lever-pushing or button-pressing. The latency dimension is the maximum length of time during which the onset of both individual responses must occur in order to constitute a cooperative response. The duration dimension of the cooperative response refers to the minimum length of time during which the individual subjects must maintain a particular, topographical position of the cooperative response.

The cooperative response in the present study was non-sequential, with a topography of the placement of mechanical styli into opposite holes in a table, a latency of 0.05 second, and a duration of any length of time greater than zero. A cooperative response occurred when both subjects inserted their styli into any one pair of the three avallable pairs of opposite holes in a table within 0.05 second of each other. Both styli had to be in their respective holes 
together for at least a fraction of the 0.05 second latency interval. Thus, if the first subject Inserted his stylus, the second subject was given 0.05 second to do the same in the opposite hole. If the first subject withdrew his stylus before the second subject had inserted his stylus, no cooperative response was recorded. If the first subject held his stylus in the hole for the full 0.05 second latency period, a cooperative response was recorded if at any time during that interval the second subject inserted his stylus in the opposite hole.

Definition of Awareness

Three classes of verbal behavior were used to objectively define awareness of the response-reinforcement contingency. These were:

A. Oppositeness requirement. A verbalization by one subfect directing his partner to put his stylus into the opposite hole, or else moving to the hole opposite his partner with a comment on oppositeness (e.g. "Let's do it In the same place," or "You do it over there," Indicating the opposite hole).

B. Time (latency) requirement. Having previously emitted a verbalization on oppositeness, 1 any verbalization

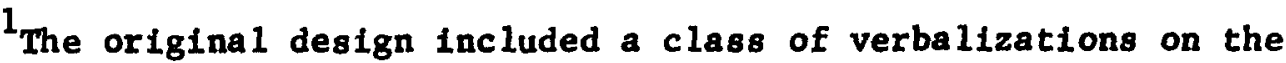
time factor without having previously emitted verbalizations on oppositeness. However, none of the pairs of subjects emitted such verbalizations so this class has been omitted. 
indicating that they must insert their styli at the same time (e.g. "Do 1t together," or "One, two, three, Go!" or "Now!").

C. A complete and accurate statement of the contingency (e.g. "You do it there when I do it here.").

It should be noted that verbalizations in response classes $B$ and $C$ are essentially the same except that $B$ verbalizations do not include a reiteration of oppositeness and $\mathrm{C}$ verbalizations do not necessarily include any previous verbalizations on the contingency. Both classes, however, include the two essential requirements of the contingency, oppositeness and latency, and therefore both may be considered verbalizations indicating full awareness.

Subjects

Ten pairs of children six through eight years of age and matched by sex served as subjects. There was less than two years difference in age between subjects in any pair. The sample was drawn from a class in the Summer Enrichment Program in the College of Education, University of Arizona.

Apparatus

The apparatus was modeled after the one described by Azrin and Lindsley (1956). Two children were seated at the opposite sides of a table with three holes and a stylus in front of each child. A wire screen down the center of the table prevented each child from mantpulating the other child's stylus (see Figure 1). Cooperative and 


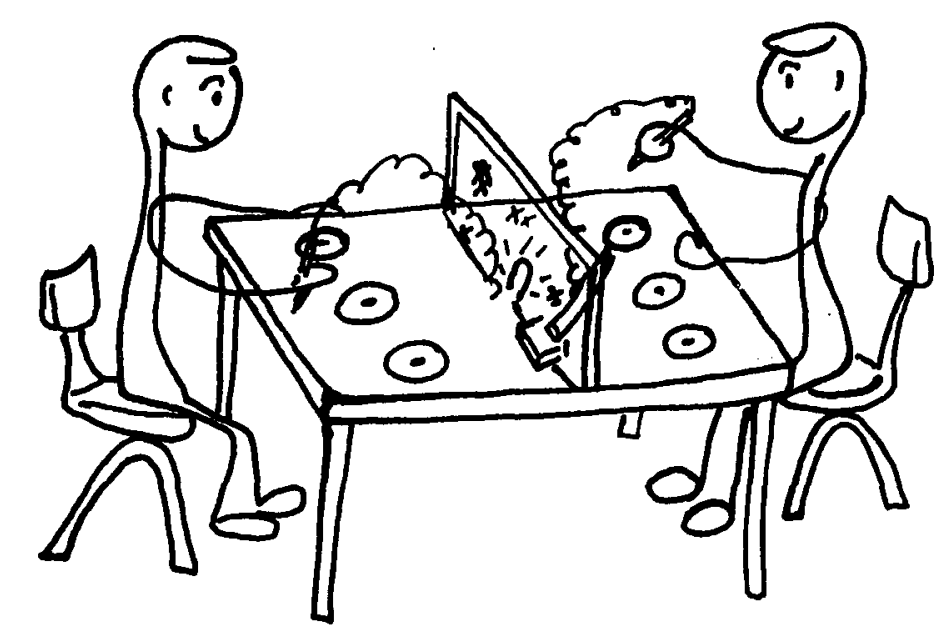

Figure 1

Experimental Table at which the Subjects were Seated

Individual noncooperative responses were recorded on seven channels of a 20 channel Esterline-Angus recorder. The first six channels on the Esterline-Angus recorder were used to record individual responses from each of the six holes. The seventh channel recorded only cooperative responses. Channels elght, nine, and ten were connected to manually operated keys, each of which represented one of the three classes of verbal behavior described above.

Whenever a cooperative response was emitted a red light in the center of the experimental table flashed, a single-tone door chime sounded, and a single MOM was delivered by an automatic MSM dispenser through a tube leading from the control room into a cup 
placed between the subjects and accessible to both. The room in which the children were seated contained only the experimental table in order to minimize the number of behaviors in which the subjects might engage. Wires from the underside of the experimental table, the inter-communication system microphone, and the door chime, as well as the reinforcement tube, led into the control room. The control room contained the rest of the experimental apparatus. A one-way mirror between the rooms allowed viewing the subjects' behavior while sound recording was possible by means of the intercom system. In addition to the EsterlineAngus recorder and the automatic M\&M dispenser, the remaining experimental apparatus consisted of a control panel which included a timer and a red light which would flash simultaneously with the light in the center of the experimental table whenever a cooperative response was made.

Procedure

Al1 pairs of subjects were run over a weekend in order to avoid returning pairs to the classroom where they would have opportunity to discuss the experiment with other subjects. One experimenter picked up the subjects at their homes and brought them to a waiting room near the laboratory. From the waiting room they were taken into the experimental room by another experimenter. Following the experimental session they were returned home and the next pair of subjects awaiting their turn were brought in.

When the subjects were brought into the experimental room they were seated at opposite sides of the table. They were given the 
following instructions: "This is a game. You play the game by putting the sticks into the holes. By playing the game together, in a certain way, you can make M\&M's drop into this cup" (pointing to the cup). "Maybe you can figure out how to play the game and win a whole lot of M\&M's. You have to play it together, in a certain way. I'm going to leave now. I' 11 be back later." These instructions were intended to induce a problem-solving set in the subjects. As the experimenter began to leave the room another experimenter, already in the control room, turned on the recording equipment and started a stopwatch. The stopwatch was used to time each 30 minute session and to note the minute during the experiment when particular behavioral observations were recorded. A continuous schedule of reinforcement was used for each pair of subjects.

One experimenter listened to the subjects' verbalizations and operated the keys for channels eight, nine, and ten on the Esterline-Angus recorder for the three classes of verbal behavior. Following the depression of any one of these keys the experimenter wrote down the key he depressed, the time on the stopwatch, and the subject's verbalization verbatim.

The other experimenter observed and recorded a number of behavioral events and the time when they occurred. For example, relevance of the conversation to the task; subjects' compliance to verify one anothers hypotheses about the contingency; discussion over the division of MSM's, time spent counting them, and whether they were eaten or saved; attending to a partner's behavior (e.g. watching him as they responded) or behaving independently; and an estimate of coordination level based on how the styli were held and the number of incomplete responses (missing 
the hole or failing to insert the styli far enough). These and other behaviors were listed on recording sheets prepared for each pair in advance of the experiment (see example in Appendix). This sheet was filled in during and immediately after each experimental session. Any other noteworthy behaviors and the time of their occurrence were recorded on the other side of the recording sheets.

After 30 minutes the subjects were interrupted. Each pair of subjects was asked, "What did you have to do to get an M\&M?" Their verbalizations and demonstrations were recorded. 


\section{RESULTS}

Conditioning Performance of Aware vs. Unaware Subjects

Five pairs were classifled as fully aware on the basis of verbalizations in response classes B (a verbalization of the latency requirement following an earlier verbalization of the oppositeness requirement) or $\mathrm{C}$ (a verbalization including both requirements). Of these five pairs, two emitted a verbalization in response class A (a verbalization of the oppositeness requirement), and then in $B$; one emitted a verbalization in $A$, then $B$, and then $C$; one emitted a verbalization in $A$, and then $C$; and one emitted a verbalization in C only. Following the experiment the question "What did you have to do to get an MEM?" resulted in two pairs emitting verbalizations in $C$, two pairs emitting verbalizations in $B$ and combining this with accurate demonstrations of the contingency, and one pair providing only an accurate demonstration.

Four pairs failed to emit a verbalization in any one of the three response classes. One pair emitted a verbalization in response class A only. To the question following the experiment the typleal reply was "Put the sticks in the holes." None emitted a verbalization in one of the three response classes and none was able to provide a demonstration of the contingency. These five pairs were classified as unaware. 
Mean percent cooperative responses (of the total of all cooperative and individual noncooperative responses) over five-minute time blocks for the five aware pairs and for the five unaware pairs is shown in Figure 2. Mean percent cooperative response rate stabilized at approximately two percent in the unaware subjects, and at approximately twenty percent in aware subjects. There is a certain probability of emitting cooperative responses through responding at random. Unaware subjects achieved a mean percent cooperative response rate of only about two percent and their increase in rate between the first and second five minute time block was less than one percent. In view of these considerations, and the fact that aware subjects achieved a mean percent cooperative response rate approximately ten times higher than the rate of unaware subjects, it may be concluded that only aware subjects conditioned. As indicated in the next section, however, some conditioning occurred prior to full awareness.

Temporal Relationship of Awareness to Conditioning

In Figure 3 the minute of full awareness has been aligned for each pair of subjects. Preawareness minutes are indicated by a minus sign and postawareness minutes by a plus sign. Mean percent cooperative responses per minute and per five minute time block are plotted. The number of pairs providing data for each segment of the graph has been indicated. The curve shows that some conditioning did occur prior to full awareness. A notable difference is evident between the mean percent cooperative response rate of the two minutes preceding the awareness minute and the previous 17 minutes of preawareness. This indicates 


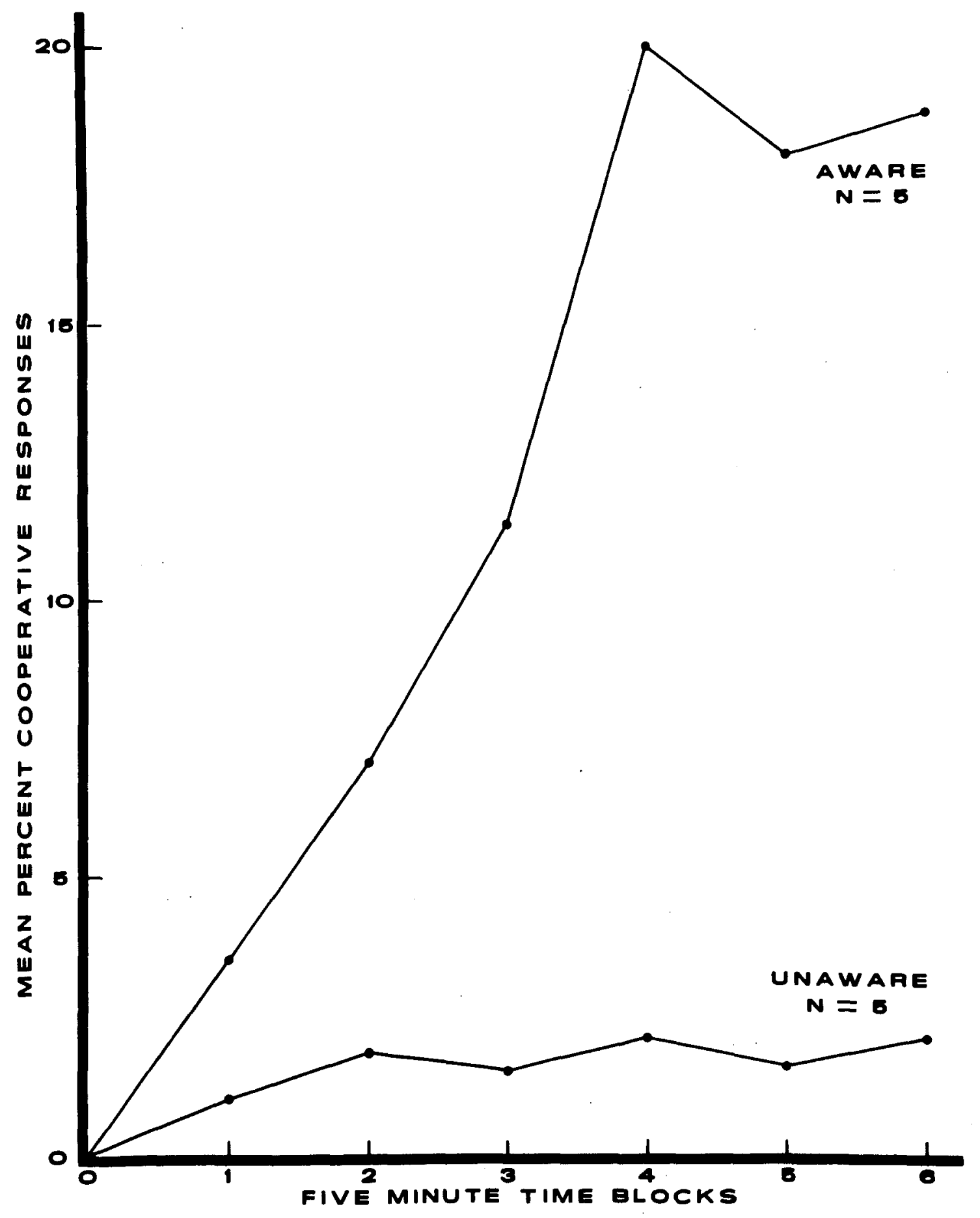

Figure 2: Mean Percent Cooperative Response Rate Curves for Aware vs. Unaware Subjects 


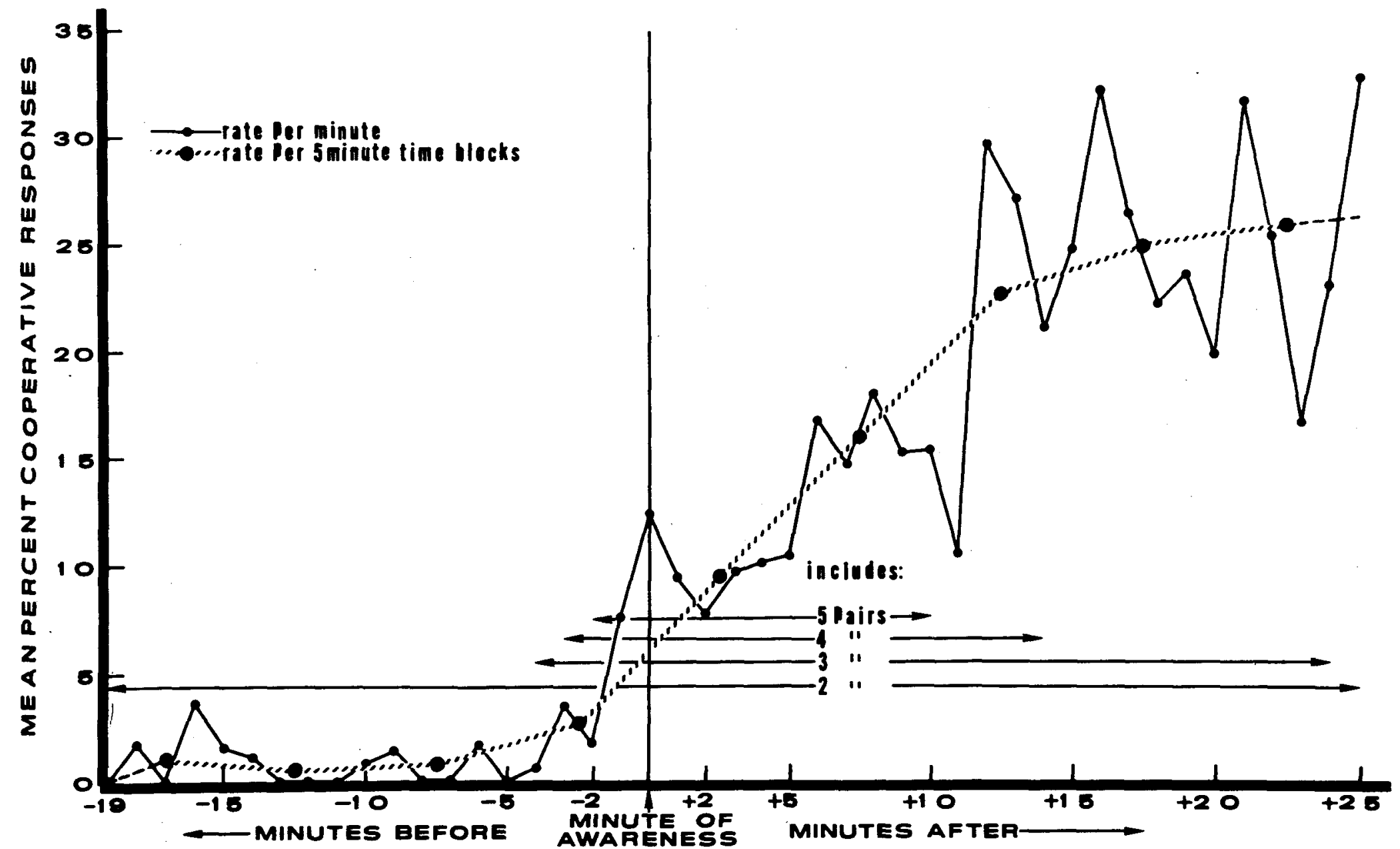

Figure 3: Mean Percent Cooperative Responses Per Minute and Per Five Minute Time Blocks for Aware Subjects

The first time block is only four minutes, not five. 
that a substantial increase in conditioning rate occurred during the two minutes prior to awareness. A statistically significant difference ${ }^{2}$ was found between the mean percent cooperative responses for the two minutes preceding the awareness minute and the two minutes following it. Thus, awareness resulted in a significant increase in the rate of the reinforced response class. The slight drop in rate for the two minutes following awareness was observed to correspond with the temporary cessation of responding to discuss dividion of the recently acquired MAM's and some consummatory behavior.

Variables Influencing Awareness

Four of the five aware pairs verbalized oppositeness before becoming fully aware (one pair completely described the contingency without previous hypotheses). Before making their oppositeness hypotheses three of these pairs had recelved some reinforcement (range: 4 to 8 ). The pair who had not received reinforcement made their hypothesis two minutes after the experiment had begun and evidently made it largely on the basis of the instructions alone, which were intended to induce a problem-solving set. The one unaware pair who had hypothesized oppositeness had received 19 reinforcements prior to the hypothesis.

The four aware pairs who verbalized oppositeness before becoming fully aware had a mean percent cooperative response rate of 2.73 before

2 All differences were tested for statistical significance by the appropriate t-test and were found to be significant beyond the 0.01 level of probability, unless otherwise indicated. 
their oppositeness verbalizations. ${ }^{3}$ Following their oppositeness verbalizations but before their verbalizations indicating complete awareness their..mean percent cooperative rate was 7.21 , an increase which approached statistical significance. Mean percent cooperative rate following full awareness was 19.00 , a significant increase $(p<0.05)$ over their rate following oppositeness verbalizations. Thus, as more complete verbalizations of the contingency were emitted, conditioning increments of increasing significance occurred. These data are summarized in Table 1.

Total rates of responding, including both cooperative and Individual noncooperative responses, were compared for the five aware and five unaware pairs. ${ }^{3}$ The mean rate of response (number of cooperative and noncooperative responses per minute) was 79.03 for aware pairs and 54.67 for unaware pairs. This difference was found to be statistically significant and thus aware pairs responded at a higher rate than unaware pairs over the entire experiment. However, mean preawareness rate for the aware pairs was 32.59 and mean postawareness rate 104.13 responses per minute. The mean number of preawareness minutes for the five aware pairs was approximately 10.5. The mean rate for unaware pairs during the first 10.5 minutes of the experimant was 51.62. This rate, and the overall rate for unaware pairs (54.67), were found to be significantly greater than the mean preawareness rate of aware subjects (32.59). This indicates that

3 Responses during the minute in which an hypothesis was made were included in the analysis by dividing the minute where channel eight, nine, or ten (corresponding to response classes A, B, and C) was initially depressed. 
TABLE 1

A Summary of Mean Percent Cooperative Response Rate Changes Before and After Verbalization of Requirements of the Contingency

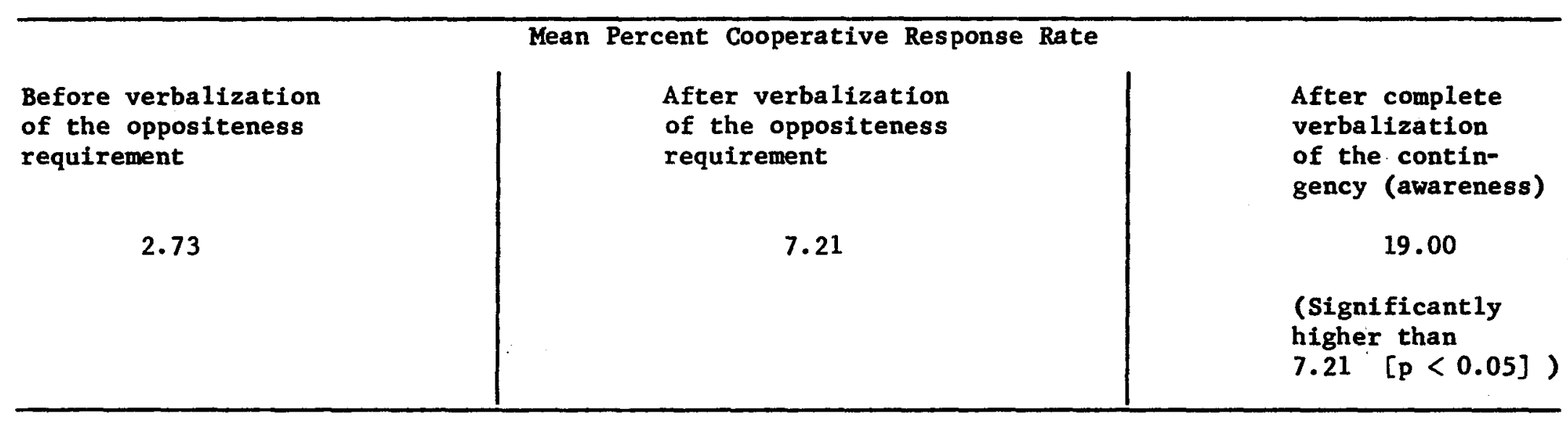


subjects who became aware responded at a significantly lower rate before they became aware than did unaware pairs during a comparable amount of time. After awareness, however, they responded at a significantly higher rate than unaware pairs. A summary of these data is found in Table 2 .

Not attending to a partner's behavior was observed to be much more frequent in unaware pairs. Very often unaware subjects would behave completely independently -- not looking at or talking to their partners -- and occasionally responded alone when the partner had stopped responding completely.

Mutual compliance to test out a partner's hypothesis characterized the pairs who became aware. It was observed in some pairs that several minutes often elapsed before compliance occurred. Typically, however, in pairs who became aware most hypotheses were eventually tested and not discarded until persistent efforts failed to result in reinforcement. In pairs who failed to become aware such compliance was less frequent, and when it did occur the duration of compliance was shorter. In fact, in the one unaware pair who verbalized the oppositeness requirement of the contingency, lack of compliance to test out the hypothesis may have been the most important factor in their fallure to condition insofar as one subject instructed his partner (the one who hypothesized the oppositeness requirement) not to do as he was doing, calling him a "copycat" for doing 80 .

A leader-follower relationship developed in four of the aware pairs and one of the unaware pairs. 
TABLE 2

A Summary of Total Response Rate Data for Aware and Unaware Subjects

Total Response Rate

\begin{tabular}{l|c|c|c} 
Aware Subjects & $\begin{array}{c}\text { Over Entire Experiment } \\
79.03\end{array}$ & 32.59 & After Awareness \\
\hline Unaware Subjects & Over Entire Experiment & $\begin{array}{l}\text { During amount of } \\
\text { time comparable to } \\
\text { before awareness time } \\
\text { of aware subjects }\end{array}$ & Over Entire Experiment \\
\hline $\begin{array}{l}\text { Probability Level of } \\
\text { Statistical Significance } \\
\text { Between Rate of Aware and } \\
\text { Unaware Subjects }\end{array}$ & 54.67 & 51.62 & 54.67 \\
\hline
\end{tabular}


Coordination level for the five aware pairs was rated "excellent, good, good, fair, and fair." Four of the unaware pairs were rated "fair," and one was rated "good." These ratings were made on the basis of how the styll were held, e.g. as a pencil or in the paim of the clenched fist, and the number of incomplete responses, e.g. missing the hole or failing to insert the stylus far enough. 


\section{DISCUSSION}

Conditioning Performance of Aware vs. Unaware Subjects

In Figure 2 it may be seen that the five pairs of subjects classified as aware conditioned, and the five pairs classified as unaware did not condition. This finding supports the conclusion of cognitive learning theorists that awareness of the response-reinforcement contingency is an essential mediating process in operant conditioning.

Since the present study was different from most studies of awareness in conditioning, the data obtained may be of particular importance in generalizing about the role of awareness in conditioning. The reinforced response class was a physical one rather than a verbal one, and it involved the behavior of two individuals (children) instead of one. Conclusions about the role of awareness in conditionIng have heretofore been based almost entirely on data from studies In which reinforcement was made contingent upon a class of verbal behavior in a single, adult subject, who generally was either a college student or a patient in a hospital. The reinforcing stimulus in the present study was candy, and the response was a free operant, whereas the reinforcing stimuli in nearly all other studies of awareness have been social ones, such as "Good," or "Mmm-hmm," and the response was often a restricted operant such as selecting one of $\mathrm{six}$ personal pronouns on a card with which to begin a sentence. In all but a very few of the other studies on awareness (e.g. Verplanck, 1955; 
Hildum and Brown, 1956), the subjects have known it was an experiment. It is unlikely that the subjects in the present study understood the experimental nature of the "game" they were playing.

The most unique feature of the present study was the way in which awareness was assessed. Reinforcement was made highly contingent on verbalizations about the contingency, since to obtain more than an occasional random reinforcement it was necessary for subjects to coordinate their responses, which made it important to verbalize about their behavior and its consequences (e.g. "If we do it together we get an MSM, so do it when I say 'Go'"). The design thus increased the probability that the occurrence of an hypothesis to a subject, and its verbalization, would occur in close contiguity. Since subjects were free to verbalize about the contingency at any time, i.e., without the presentation of discriminative stimuli to do so during the experiment as in other studies of the temporal relationship of awareness to conditioning (DeNike, 1964; Splelberger, Bernstein, and Ratliff, 1966), and since their verbalizations were recorded simultaneously with rate of emission of the reinforced response class, a sensitive record of the interaction of awareness and rate was obtained. In view of the numerous differences between the present study and other studies of awareness in conditioning, the data obtained may be of unique importance in supporting (or challenging) the conclusions of others about the role of awareness in the operant conditioning process in general. 
Temporal Relationship of Awareness to Conditioning

In Figure 3 the curve of the mean percent cooperative response rate shows a sharp increase following the minute of awareness, suggesting that awareness mediated conditioning gains. A comparison of the rate for the two minutes prior to the awareness minute with the two minutes following it showed the increase to be statistically significant. These data also support the conclusion that awareness mediates conditioning gains.

In Figure 3 it is readily apparent that some conditioning occurred prior to the awareness minute. Inspection of the data indicated that rate during the two minutes prior to the awareness minute was notably higher than rate during the previous 17 minutes of preawareness.

Since demonstrable conditioning occurred prior to awareness, and an even further increase in rate of conditioning occurred following awareness, the theory of Postman and Sassenrath is supported. It would appear that awareness is both "a result of past improvement and a condition of further improvement." However, the data do not necessarily support their contention that the "past improvement," i.e., the preawareness conditioning, is a function of the automatic effects of reinforcement, if it is meant by this that reinforcement is both a necessary and sufficient condition to bring about preawareness conditioning and hence awareness.

The two cognitive studies in which awareness was assessed during the experiment (DeNike, 1964; Spielberger, Bernstein, and Rat11ff, 1966) resulted in data which the authors interpreted as showing the necessity 
for awareness to occur before conditioning occurs. In the light of the data from the present experiment it could be argued that these two earlier studies did not employ a sufficiently sensitive measure of the temporal relationship of awareness to conditioning rate. In both of these studies awareness was assessed following each block of 25 words. It was found that conditioning began to occur during and following the word block after which a correct hypothesis of the contingency was verbalized. Subjects were not free to verbalize an hypothesis at the precise moment it occurred to them, as was the case in the present study. Thus, it is possible that significant increments in conditioning did occur prior to their hypothesis, which they had to wait to report at the end of the word block.

Splelberger and DeNike have also questioned why, if reinforcement has an automatic effect on behavior, did it fail to affect the conditioning of unaware subjects or that of aware subjects on preawareness word blocks. This evidence contraindicates the "automatic" effects of reinforcement, if this is taken to mean that reinforcement alone is a sufficient condition for bringing about conditioning. It would also seem that other conditions, in addition to reinforcement, are necessary to operantly condition human behavior.

There is good evidence that awareness does mediate a high rate of conditioning, and lack of awareness results in little or no conditioning (e.g. DeNike and Spielberger, 1963; DeNike, 1964; Dulany, 1962; Lanyon, 1964; Levin, 1961; Spielberger, Bernstein, and Ratliff, 1966; Spielberger, Levin, and Shepard, 1962; Spielberger, Berger, and Howard, 1963). Evidence from the present study supports the Postman 
and Sassenrath theory that one condition necessary to bring about awareness is substantial increments in rate just prior to awareness. However, there are several other variables which may also influence awareness.

Variables Influencing Awareness

It is necessary at the outset of this section to point out that the effects of the variables discussed here may very well be on the preawareness conditioning alone, which in itself may be both a necessary and sufficient condition to bring about awareness. These variables are only regarded as being involved in the process of becoming aware in some manner which as yet is not entirely clear. The data do not permit a more explicit interpretation of their involvement.

With regard to the Postman and Sassenrath supposition that "verbalization must be considered as a function of the conditions of reinforcement," it has already been stated that the data from this experiment do not support the idea that reinforcement alone can produce awareness. Adams (1957) maintains that partially correct hypotheses of the contingency, etther implicitly held or explicitly stated, are essential to becoming fully aware. Some support for this supposition Is found in the present data insofar as four of the aware pairs verbalized oppositeness prior to a complete verbalization of the contingency. It was found that their mean percent cooperative rate increased substantially following their verbalizations of oppositeness (see Table 1). A significant increase in rate was found following complete awareness. It could be argued, therefore, that their partially 
correct hypotheses, which increased their mean percent cooperative rate, were essential to becoming fully aware. However, it is not reasonable to infer an intrinsically held partially correct hypotheses in the one aware pair whose only verbalization was a full statement of the contingency. Nor is it possible to regard partially correct hypotheses as more than a possible necessary condition for awareness insofar as one unaware pair verbalized oppositeness and failed to become fully aware. The data from this experiment are most reasonably interpreted as supporting the possibility that partially correct hypotheses are a necessary condition for awareness. Insufficient data were obtained to evaluate possible antecedent conditions for the partially correct hypotheses themselves.

There seems to be little doubt that reinforcement is necessary for awareness to occur. On the basis of the data in this study, in which all aware pairs of subjects received reinforcement prior to becoming aware, and all unaware pairs were occasionally reinforced during the experiment, that reinforcement is a necessary but not sufficient condition for awareness.

In their attempt to account for the findings of cognitive studies on awareness, Spielberger and DeNike have indicated that reinforcement and nonreinforcement "convey differential information and provide differential incentive to the subject" (1966, p. 320). By this they apparently mean that the reinforcing stimulus, or more accurately the contingent stimulus, possesses both discriminative and reinforcing properties. Indeed, without consequences to behavior it is difficult to imagine how hypotheses are suggested, and even more difficult to 
Imagine how they are confirmed or disconfirmed. Thus, in the operant conditioning of behavior, it would appear that a stimulus, which possesses both reinforcing and discriminative properties, must be made contingent upon the response class to be conditioned, and that this stimulus is a necessary but not sufficient condition for awareness. It could be speculated that in the present study, and perhaps in other studies, the $S^{D}$ properties of the contingent stimulus were of greater importance in leading to awareness, following which the reinforcing properties were more important in order to maintain the conditioned behavior. That is, during preawareness subjects must discriminate the characteristics of their behavior that will be reinforced, but once having done so, the reinforcing consequences of the behavior are necessary to maintain it over a period of time. Total rate of responding is another variable likely to be involved in bringing about awareness of the contingency. On a priori grounds it might be expected that a higher total rate would increase the probability of reinforcement and therefore increase the probability of becoming aware. It was found that the aware pairs responded at a significantly higher rate than unaware pairs over the entire experiment (see Table 2). However, their preawareness rate was signfificantly lower than both the overall rate for unaware pairs, and the rate of unaware pairs during a period of time comparable to the preawareness time of aware pairs. After awareness, the rate of aware pairs was significantly higher than the overall rate of unaware pairs. Therefore, these data do not support the supposition that awareness might be a function of higher total rate. To the contrary, 
they suggest that a higher total rate is a function of awareness. They also suggest that a fairly low rate may be important in bringing about awareness. Conversely, a higher rate may make it less likely that awareness w111 occur. Perhaps a lower rate affords easier discrimination of the one response, out of all of the responses the subjects are emitting, which is contingent upon the reinforcing stimulus. Higher rate subjects may emit responses which intervene between the correct response and its reinforcement, whereas lower rate subjects may not emit as many intervening responses. Higher rate subjects, therefore, are not given as much opportunity to discriminate which of several behaviors resulted in reinforcement. These data may be comparable to the amount of time taken between responses by subjects in verbal conditioning experiments. The time for blocks of trials, or the time between responses, have not been reported in verbal conditioning studies. Such a measure might show, however, that subjects who become aware take more time between responses on preawareness trials than they do on postawareness trials. Similarly, it might be found that unaware subjects have a mean time between responses which is between the pre- and postawareness mean time for aware subjects. This would suggest that time is needed for thinking up hypotheses and observing the consequences in testing them, but that once an hypothesis is confirmed this time is no longer needed.

With regard to verbal conditioning experiments, Eriksen (1960) suggests that subjects "attention" may be important in fnfluencing awareness and/or conditioning. Attention is not easily measured in verbal conditioning experiments and has not been reported as a signtficant 
variable. In verbal conditioning studies a single subject per session is used, he is usually an adult, and the experimenter's. instructions probably have enough stimalus control over his behavior to result in a fairly even amount of attention in all subjects. At least it is difficult to measure behavioral manifestations of differences in the attention of adult subjects who have been instructed to carry out a specific task. In a cooperative study using children as subjects, however, the same instructions are likely to exert differing amounts of stimulus control over their behavior. This is especially true when, as in the present study, the instructions only describe the "game" without actually asking the subjects to participate, and they are therefore relatively free to attend to the game or not to attend to it. The effects of attention to the task were therefore fairly easy to observe in the present study. It was found that pairs who became aware of the conting?ncy were much more attentive to one anothers behavior. They watched each other responding more, and spent more time in relevant conversation about the task, compared with unaware pairs. Apparently, a leader who directs the pair's attention to relevant aspects of the task for purposes of testing out hypotheses, etc., is effective in leading to awareness. Unaware pairs typically engaged in more independent behaviors and more of their conversation involved irrelevancies to the task. Moreover, unaware pairs very often failed to comply tn order to test a partner's hypothesis about the contingency. When they did comply, unaware subjects usually did so for a shorter period of time, thus decreasing the liklihood of getting reinforced. This failure to be reinforced for compliance in testing a 
partner's hypothesis, which was usually Incorrect, probably also decreased the liklihood of compliance on future occastons. Subjects' becoming aware is probably influenced by the nature of the conditioning task. Krasner and Ullman (1963, p. 200) write that, "In assessing the effects of awareness, as well as other verbal conditioning phenomena, there has usually been insufficient attention focused on certain differences in the nature of the task, the differences between a restricted, elicited operant situation such as the Taffel pronoun sentence completion task and the free operant, emitted, Greenspoon word-saying (task)... ." In a review of the literature (Vogler, 1966a), it was found that each of these procedures has been used extensively by both operant and cognitive investigators, and that the results have been the same using either one. The task in the present study was unlike any in the verbal conditioning experiments and the results of the study may therefore be of particular significance in generalizing about awareness and operant conditioning.

The 0.05 second latency interval was chosen because it was found in pllot data that a longer latency resulted in all of the pairs becoming aware. The combined effects of the topography of the cooperative response, which was somewhat difficult for the subjects' age, and the very brief latency, were considered likely to result in some pairs becoming aware and others as remaining unaware. In general, it was observed that pairs who became aware were slightly better coordinated than unaware pairs. They were better able to control the emission of the precise responses they intended to make. 
The above considerations and observations on task variables are unique to this study of awareness and conditioning. A free operant, cooperative response with a very brief latency and a rather difficult topography for subjects in the age range used, very likely influenced awareness by favoring better coordinated pairs.

In summary, the conditions or variables found likely to influence awareness were substantial increments in conditioning just prior to awareness, partially correct hypotheses, reinforcement, total response rate, attention to the task, mutual compliance to test hypotheses, and characteristics of the conditioning task. Preawareness conditioning was supported as a necessary condition for awareness; it is possible that preawareness conditioning is also a sufficient condition for awareness and the other variables discussed have their effects on it (the data do not permit a more explicit interpretation). The possibility that partially correct hypotheses are involved in bringing about full awareness was supported. A stimulus with both reinforcIng and discriminative properties, made contingent upon the response class to be conditioned, appeared to be a necessary but not sufficient condition for awareness. A relatively low preawareness total response rate, probably facilitating discrimination of the contingent stimulus, appeared to be influential in leading to awareness. Attention to the conditioning task, a variable itself influenced by the stimulus control of the instructions, was Involved in becoming aware. Mutual compliance to test hypothesees, or the development of an efficient leader-follower relationship, was observed to be important in leading to awareness. The latency and topography of the cooperative response employed were 
observed to influence the precise and intentional emission of subjects' responses and therefore their liklihood of becoming aware of the contingency.

From these data it may be concluded that manipulatable conditions which would enhance the liklihood of awareness, and hence conditioning, are: a response with a longer latency and a simpler topography; a restricted operant which would slow the total rate of response and provide time between responses to observe the consequences of each response emitted; instructions which induce a problem-solving set.

Insofar as several of the variables influencing awareness probably interact with, or in some way are influenced by, reinforcement, instructions, and historical variables, it may be important for future research to study them in order to arrive at a more complete explanation of the antecedent conditions for awareness. Such a study might investigate historical variables by providing one group of subjects with a history of a high total response rate and another group with a low total response rate. For example, a restricted operant could be used to increase the time between responses by removing the manipulandum briefly, giving subjects a history of lower total rate of responding. Another group of subjects could be given a history of a higher total response rate by using a free operant, which would permit them to respond at a considerably higher rate. Then in a somewhat different test situation to follow, it could be determined whether more subjects with a history of responding at a low rate would become aware, and in a shorter time, than subjects with 
a history of responding at a higher rate, as would be predicted from the data in the present study on total response rate and awareness. Awareness is a symbolization of the relationship between one's behavior and its consequences. Defined as verbalization of the responsereinforcement contingency, awareness was found to be essential to the operant conditioning of a cooperative response in the present study. As a cognitive process which may be an essential mediating event in the conditioning of many human behaviors, a detailed knowledge of the process itself and the conditions affecting it, particularly those which are more manipulatable, may have significant implications for behavior modification.

In this study an attempt was made to clarify the mediational role of awareness in conditioning, in particular to determine the temporal relationship of awareness to conditioning, and to determine conditions which may be involved in becoming aware. Assuming that awareness is essential to the conditioning of many human behaviors, then perhaps the best direction for future research is to more clearly determine the conditions which lead to awareness. These conditions may be found to have systematic effects not only on the acquisition of the behavior, but perhaps also on its extinction and generalization properties. 
SUMMARY

In this paper some of the theoretical issues on the role of awareness In operant conditioning studies are discussed. To date nearly all of the studies on awareness have involved the conditioning of verbal behavior. Investigators with an operant conditioning orientation have produced evidence that conditioning can occur without awareness, whereas workers from a cognitive learning theory point of view, employing somewhat different experimental procedures, have obtained results supporting the hypothesis that conditioning only occurs in subjects who become aware of the response-reinforcement contingency. Moreover, cognitive theorists have obtained recent evidence indicating that increments in conditioning performance occur only after awareness, whereas one theory, that of Postman and Sassenrath, maintains that some conditioning occurs prior to awareness and that awareness is both a result of past improvement and a condition of further improvement in conditioning performance. The present study was different from other studies of awareness in several ways. The reinforced response class was a physical one rather than a verbal one and Involved the behavior of two individuals instead of one, candy instead of a verbal stimulus was used as the reinforcer, the experimental nature of the study was not apparent to the subjects, who were children rather than adults, and most importantly, the experimental design increased the probability that the occurrence of an hypothesis to a subject and its verbalization would occur in 
close contiguity, and these verbalizations could be recorded simultaneously with rate of conditioning. The latter difference was unique among studies on awareness in providing a sensitive measure of the temporal relationship of awareness to conditioning rate. The cooperative response was defined according to a four-dimensional scheme involving the sequential vs. non-sequential, latency, duration, and topography dimensions of the response. Three classes of verbal behavior were used to objectively define the requirements of awareness of the response-reinforcement contingency. Ten pairs of children six to eight years of age served as subjects. On the basis of verbalizations during the experiment, five pairs were classified as aware and five as unaware. Only aware subjects conditioned thus supporting the hypothesis that awareness is necessary for conditioning to occur. An increase in conditioning rate was observed just prior to awareness, and an even greater increase occurred following awareness. These data support the Postman and Sassenrath position that awareness is both the result of past improvement and a condition of further improvement. Since all unaware subjects received some reinforcement and yet failed to become aware, the idea that the effects of reinforcement are "automatic," in the sense that reinforcement is a sufficient condition to bring about awareness, was not supported. The data suggest that reinforcement is a necessary condition for awareness to occur, and that other variables influencing awareness are partially correct hypotheses, total response rate, attention to the task, mutual compliance to test hypotheses, and characteristics of the conditioning task. Each of these variables probably interacts with, or in some way is influenced by, reinforcement, 
instructions, and historical variables. Manipulatable conditions which would enhance the liklihood of awareness, and hence conditioning, are: a response with a longer latency and a simpler topography; a restricted operant which would slow the total rate of response and provide time between responses to observe the consequences of each response emitted; instructions which induce a problem-solving set. As a cognitive process which may be an essential mediating event in the conditioning of many human behaviors, a detailed knowledge of the process itself and the conditions affecting it may have significant implications for behavior modification. The conditions which lead to awareness may be found to have systematic effects not only on the acquisition of the behavior, but perhaps also on its extinction and generalization properties. 


\section{APPENDIX}

Example of Recording Sheet

\begin{tabular}{l|l|l|l|l|l|l|}
\hline \hline Pair & Sex & Age & $\begin{array}{l}\text { PCI ("What did you } \\
\text { have to do to get } \\
\text { an Msa?") }\end{array}$ & $\begin{array}{l}\text { Relevance of } \\
\text { conversation } \\
\text { to the task }\end{array}$ & $\begin{array}{l}\text { Attending to } \\
\text { partner's } \\
\text { behavior }\end{array}$ \\
\hline$\cdots-$ & -- & -- & $\begin{array}{l}\text { Verbalizations } \\
\text { verbatim; descrip- } \\
\text { tion of demonstra- } \\
\text { partner's } \\
\text { hypothesis }\end{array}$ & & $\begin{array}{l}\text { Watching him } \\
\text { while respond- } \\
\text { ing, talking } \\
\text { to him, vs. } \\
\text { independent } \\
\text { behavior. }\end{array}$ \\
\hline
\end{tabular}

\begin{tabular}{|c|c|c|c|c|c|}
\hline $\begin{array}{l}\text { Behaviors related } \\
\text { to the MSM's }\end{array}$ & $\begin{array}{l}\text { Leader-Follower } \\
\text { Relationship }\end{array}$ & $\begin{array}{l}\text { Responding } \\
\text { together } \\
\text { from one } \\
\text { set of } \\
\text { opposite } \\
\text { holes to } \\
\text { another }\end{array}$ & $\begin{array}{l}\text { One } S \text { only } \\
\text { responding }\end{array}$ & $\begin{array}{l}\text { Grinding } \\
\text { or jam- } \\
\text { ing styli } \\
\text { into holes }\end{array}$ & $\begin{array}{l}\text { Coordination } \\
\text { rating }\end{array}$ \\
\hline $\begin{array}{l}\text { Discussion and } \\
\text { arguments about } \\
\text { their division; } \\
\text { fair-unfair div- } \\
\text { ision; time spent } \\
\text { counting them; } \\
\text { eating vs. } \\
\text { saving. } \\
\end{array}$ & $\cdots \cdots$ & $-\cdots-\cdots \cdots$ & 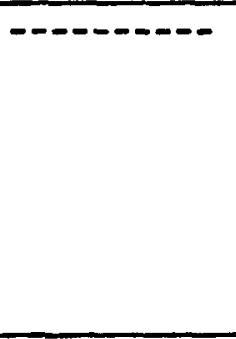 & $\cdots-\infty-\infty$ & $\begin{array}{l}\text { Poor to excel- } \\
\text { lent based on } \\
\text { how stylus held } \\
\text { and number of } \\
\text { incomplete } \\
\text { responses. }\end{array}$ \\
\hline
\end{tabular}




\section{LIST OF REFERENCES}

Adams, J. K. Laboratory studies of behavior without awareness. Psychological Bulletin, 1957, 54, 383-405.

Azrin, H. H. and 0 . R. Lindsley. The reinforcement of cooperation between children. Journal of Abnormal and Social Psychology, 1956, 52, $100-102$.

DeNike, L. D. The temporal relationship between awareness and performance in verbal conditioning. Journal of Experimental Psychology, $1964,68,521-529$.

DeNike, L. D. and C. D. Spielberger. Induced mediating states in verbal conditioning. Journal of Verbal Learning and Verbal Behavior, $1963, \underline{15}, 931-938$.

Dulany, D. E. The place of hypotheses and intentions: an analysis of verbal control in verbal conditioning. Journal of Personality, 1962, 30, (Supp1.), 102-129.

Eriksen, C. W. Figments, fantasies, and follies: a search for the subconscious mind. In C. W. Eriksen (ed.), Behavior and awareness: a symposium of research and interpretation. Durham, N. C.: Duke University Press, 1962, pp. 3-26.

Greenspoon, J. The reinforcing effect of two spoken sounds on the frequency of two responses. The American Journal of Psychology, $1955, \underline{68}, 409-416$.

Greenspoon, J. Verbal conditioning and clinical psychology. In A. J. Backrach (ed.), Experimental foundations of clinical psychology. New York: Basic Books, 1962, pp. 510-553.

Krasner, L. Studies of the conditioning of verbal behavior. Psychological Bulletin, 1958, 55, 148-170.

Krasner, L. and L. P. Ullmann. Variables effecting report of awareness in verbal conditioning. The Journal of Psychology, 1963, 56, 193-202.

Lanyon, R. I. Verbal conditioning and awareness in a sentence-construction task. The American Journal of Psychology, 1964, 77, 472-475.

Levin, S. M. The effects of awareness on verbal conditioning. Journal of Experimental Psychology, 1961, 67-75. 
Postman, L. and J. M. Sassenrath. The automatic action of verbal rewards and punishments. Journal of Genera 1 Psychology, 1961, 65, 109-136.

Salzinger, K. Experimental manipulation of verbal behavior: a review. Journal of General Psychology, 1959, 61, 65-94.

Spielberger, C. D. The role of awareness in verbal conditioning. Journal of Personality, 1962, 30, 73-101.

Spielberger, C. D., S. M. Levin, and M. Shepard. The effects of awareness and attitude toward the reinforcement on the operant conditioning of verbal behavior. Journal of Personality, 1962, 30, 106-121.

Spielberger, C. D., A. Berger, and K. Howard. Conditioning of verbal behavior as a function of awareness, need for social approval and motivation to receive reinforcement. Journa 1 of Abnorma 1 and Social Psychology, 1963, 67, 241-246.

Spielberger, C. D., I. H. Bernstein, and R. G. Ratiff. Information and incentive value of the reinforcing stimulus in verbal conditioning. Journal of Experimental Psychology, 1966, 71, 26-31.

Spielberger, C. D. and L. D. DeNike. Descriptive behaviorism versus cognitive theory in verbal operant conditioning. Psychological Review, 1966, 73, 306-326.

Verplanck, W. S. The operant, from rat to man: an introduction to some recent experiments on human behavior. Transactions of the New York Academy of Sciences, 1955, 17, 594-601.

Vogler, R. E. Awareness and verbal conditioning: a controversy of theoretical positions. Preliminary examination paper, 1966a.

Vogler, R. E. Analysis of a cooperative response. Unpublished Mastex's Thesis, 1966b. 